\title{
CHLORATE TOXICITY IN ASPERGILLUS NIDULANS: THE SELECTION AND CHARACTERISATION OF CHLORATE RESISTANT MUTANTS
}

\author{
D. J. COVE \\ Department of Genetics, University of Cambridge, Milton Road, Cambridge CB4 IXH
}

Received 3.x.75

\section{Summary}

\begin{abstract}
Mutation in at least ten genes can result in chlorate resistance in Aspergillus nidulans. Mutation in seven of these genes also results in the inability to use nitrate as nitrogen source. The various classes of resistant mutant obtained occur in different proportions, depending on whether or not a mutagenic trea tment is employed, and also on which nitrogen source is used for selection. The principal effect of mutagen arises because mutations in the niaD gene, the nitrate reductase structural gene, are relatively much commoner when no mutagen is used than after treatment with $\mathrm{N}$-methyl- $\mathrm{N}^{\prime}$-nitro- $\mathrm{N}$-nitrosoguanidine. This may be connected with the finding that deletions involving the niaD gene are relatively more common among samples of spontaneous nia $D$ mutants. Some of these deletions extend to the neighbouring niiA gene, the structural gene for nitrite reductase. The selection procedures used were designed to avoid bias in favour of any particular chlorate resistant phenotype. Even if biases existed however, these could not account for the variation found from nitrogen source to nitrogen source in the proportions of certain resistant classes having apparently identical chlorate resistance phenotypes.
\end{abstract}

\section{INTRODUCTION}

DAta presented by Cove (1976) shows that chlorate toxicity in Aspergillus nidulans is not due to nitrate reductase-catalysed conversion of chlorate to chlorite, a mechanism proposed for other organisms (Aberg, 1947). Although the catalytic activity of nitrate reductase is not involved, nitrate reductase probably plays some role in mediating chlorate toxicity, as some, but not all, mutants lacking nitrate reductase are chlorate resistant. Mutation in a number of genes can abolish nitrate reductase (Cove and Pateman, 1963; Pateman, Rever and Cove, 1967). These include the niaD and five $c n x$ genes which together contribute to the activity of nitrate reductase, the niaD gene being the structural gene for the nitrate reductase apo-enzyme, and the cnx genes directing the synthesis of a co-factor shared by nitrate reductase and xanthine dehydrogenases I and II (Pateman, Cove, Rever and Roberts, 1964; MacDonald and Cove, 1974; Scazzocchio, 1974). Mutations in the niaD gene and all five $c n x$ genes, which abolish nitrate reductase, may or may not lead to chlorate resistance (Cove, 1975).

Nitrate reductase activity can also be lost as a result of mutation in the $\operatorname{nir} A$ gene which, it is postulated, specifies a regulatory protein necessary for the synthesis of nitrate and nitrite reductase (Cove, 1970). Although nir $A^{-}$ mutants produce only low levels of nitrate reductase, they show a pattern of chlorate resistance qualitatively different from niaD and $c n x$ mutants (Cove, 1975). The interactions between nir $A^{-}$mutations and niaD or cnx mutations are not straightforward, and there is no simple pattern of epistasy. Cove 
(1975) has therefore suggested that both the nir gene product and the nitrate reductase holo-enzyme (i.e. the niaD gene product + the co-factor specified by the five $c n x$ genes) are directly involved in the mediation of chlorate toxicity. Chlorate resistant mutations in the niaD gene and all five $c n x$ genes have similar phenotypes, and doubly mutant strains carrying mutations leading to chlorate resistance, either in two different $c n x$ genes, or a $c n x$ gene and the niaD gene, are no more chlorate resistant than the component single mutants. Mutational alteration, either of the nitrate reductase apo-protein (the niaD gene product) or of the co-factor, appears therefore to result in chlorate resistance by the same mechanism. However, preliminary experiments showed that, if chlorate resistant mutants were selected, the proportion of niaD and $c n x$ mutants among them varied depending on the nitrogen source used, indicating perhaps that the relative roles of the niaD gene product and the co-factor varied with different nitrogen sources. This paper describes the results of experiments which confirm that, under certain circumstances, the nitrogen source used for the selection of chlorate resistant mutants does affect the relative proportions of niaD and $c n x$ mutants obtained. In addition these experiments show that the spectrum of resistant mutants varies with the sensitive strain used, and also according to whether or not a mutagen is used.

\section{Materials and Methods}

(i) Origin of chlorate-sensitive strains used in selection experiments

an $A \mathrm{l} y A \mathrm{l}$ and $b i A \mathrm{l}$ were originally obtained from the Department of Genetics, University of Glasgow; biAl puA2 pyro $A 4$ was derived by crossing from two further Glasgow strains, biAl puA2 and $y A 1$ pyro $A 4$; and $y A 1 p u A 2$ and $p u A 2$ by crossing from biAl puA2 pyroA4 and Glasgow strain proA6 pabaA6 $y A$ l. None of these strains carries a translocation. Gene symbols are those in standard use (Clutterbuck, 1974).

(ii) Media

Media used were those described by Cove (1966).

\section{(iii) Mutagenic treatment}

Conidiospores were treated with $\mathrm{N}$-methyl-N'-nitro-N-nitrosoguanidine (NTG) according to the method of Adelberg, Mandel and Chen (1965) as modified by Alderson and Hartley (1969), so that survival was between 5 and 15 per cent.

\section{(iv) Selection of chlorate resistant strains}

Method A. Conidiospores were inoculated on to the chlorate containing medium, 10 inocula per petri dish, and incubated for 3 to 4 days at $37^{\circ}$, after which resistant sectors developed. Only one resistant sector was picked from each inoculum. Where more than one resistant sector had developed from a single inoculum, the sector nearest to a fixed reference direction was chosen to avoid bias in favour of a particular morphology of sector. Resistant sectors were subcultured on to appropriately supplemented minimal medium having ammonium as nitrogen source, and subsequently re-isolated from single conidiospores. To ensure that, where no mutagen was used, all resistant sectors obtained had independent origins, the original conidiospore 
inocula were derived each from a different colony which had in turn developed from a single conidiospore on appropriately supplemented minimal medium containing nitrate as nitrogen source. Where mutagenised conidiospores were used this procedure could not be followed; the mutagenised conidiospores were derived from several thousand independent colonies growing on appropriately supplemented minimal medium containing nitrate as nitrogen source. Mutagenised conidiospores were used as a suspension (containing $\mathrm{ca}$. $10^{7}$ surviving conidiospores $/ \mathrm{ml}$ ) obtained after the mutagenic treatment, and were inoculated with a twisted double-wired needle. This procedure transfers several thousand viable spores.

Method $B$. The conidiospores after mutagenic treatment were diluted to give a density of $10^{8}$ treated spores per $\mathrm{ml}$. This suspension was further diluted 80 -fold into the appropriate selective medium, which had been melted, and cooled to $45^{\circ}$. $4 \mathrm{ml}$ of this mixture was then pipetted on to the surface of a similar solid medium in a petri dish. These media contained sodium desoxycholate $(800 \mathrm{mg} / \mathrm{l})$ to induce the formation of micro-colonies (Mackintosh and Pritchard, 1963). Resistant micro-colonies developed after 4-5 days' incubation at $37^{\circ}$. These were subcultured and re-isolated as described for method A above. The sample of resistant mutants was picked to ensure that there was no bias in favour of a particular morphology of resistant colony, except that only colonies which conidiated were chosen. Where spontaneous mutants were selected by this method, a procedure similar to that for induced mutants was followed, except that mutagen was not used. These procedures each gave between 100 and 300 resistant colonies per petri dish.

(v) Selection of nitrate non-utilising mutants from putrescine requiring auxotrophs, by the use of putrescine starvation

Putrescine auxotrophs, when inoculated on to media which do not contain putrescine, grow with a restricted morphology. Mutants unable to utilise nitrate, when inoculated on media with nitrate as the only nitrogen source, grow with a sparse but spreading morphology characteristic of nitrogen starvation. Nitrate non-utilising, putrescine-requiring double mutants inoculated on nitrate medium, in the absence of putrescine, show the sparse spreading morphology. This finding (Herman and Clutterbuck, 1966) can be exploited to select, in putrescine auxotrophs, mutations leading to an inability to utilise nitrate. A suspension from a mutagenic treatment containing about $10^{7}$ surviving conidiospores per $\mathrm{ml}$ was inoculated with a twisted double-wired needle to give ten inocula per petri dish on to media containing nitrate as nitrogen source, but no putrescine. After 4-5 days' incubation at $37^{\circ}$, vigorous but sparse sectors developed from some inocula, and mycelial inocula were taken from these and transferred to medium containing putrescine and having ammonium as nitrogen source. The selected strains were subsequently re-isolated from a single conidiospore. Only one sector was picked from each inoculum. Where more than one sector had developed from a single inoculum, the sector nearest a fixed reference direction was chosen.

\section{(vi) Classification of selected strains}

The strains selected by the various procedures were inoculated on to master plates of complete medium, and then classified by replica plating on 
to test media according to the criteria listed in table 1. Allocation of $c n x$ strains to complementation groups, and confirmation of the classification of other types was carried out by testing for complementation for the use of nitrate in heterokaryons with stock representative strains of each type.

\section{TABLE 1}

Criteria used for the classification of selected strains

\begin{tabular}{|c|c|c|c|c|c|c|c|}
\hline & & tilisati & as $\mathrm{N}$ : & arce of: & & Resistant $t$ & chlorate or \\
\hline & $\mathrm{NH}_{4}^{+}$ & $\mathrm{NO}_{3}^{-}$ & $\mathrm{NO}_{2}^{-}$ & Hypoxanthine & excretion & arginine & uric acid \\
\hline ii & $\checkmark$ & $x$ & $\checkmark$ & $\checkmark$ & No & Yes & Yes \\
\hline & $\checkmark$ & $x$ & $\checkmark$ & $x$ & No & Yes & Yes \\
\hline & $\checkmark$ & $x$ & $x$ & $\checkmark$ & No & Slightly & Yes \\
\hline & $\checkmark$ & $x$ & $x$ & $\checkmark$ & Yes & No & No \\
\hline nia & $\checkmark$ & $x$ & $x$ & $\checkmark$ & No & Yes & Yes \\
\hline UUN & $\checkmark$ & $\checkmark$ & $\checkmark$ & $\checkmark$ & Slight & (Yes) & (Yes) \\
\hline ild-type & $\checkmark$ & $\checkmark$ & $\checkmark$ & $\checkmark$ & Slight & No & No \\
\hline
\end{tabular}

Ammonium was added as the $(+)$ tartrate at a concentration of $5 \mathrm{mM}, \mathrm{NO}_{3}^{-}$and $\mathrm{NO}_{\overline{2}}^{-}$ as $\mathrm{Na}$ salts at $10 \mathrm{mM}$, and hypoxanthine at $100 \mathrm{mg} / 1$. NO$-\frac{1}{2}$ excretion was tested by taking colonies which had grown for 24 hours at $37^{\circ}$ on petri dishes of minimal medium with urea as nitrogen source, and flooding with $3 \mathrm{M}$ sodium nitrate solution; after 45 minutes incubation at $37^{\circ}$ the nitrate solution was discarded and the presence of nitrite was detected colorimetrically by the addition of $1 \mathrm{ml}$ of a 1 per cent $(\mathrm{w} / \mathrm{v})$ solution of sulphanilamide dissolved in three parts water to one part concentrated $\mathrm{HCl}$, followed by $1 \mathrm{ml}$ of a 0.02 per cent (w/v) aqueous solution of N(l-naphthyl) ethylenediamine hydrochloride (Cove, 1966). Nitrite excretion was visible as a pink halo around a colony. Chlorate resistance was scored on media containing $100 \mathrm{mM} \mathrm{KClO}{ }_{3}$ and either $10 \mathrm{mM} \mathrm{L}$-arginine $\mathrm{HCl}$ or $100 \mathrm{mg} / \mathrm{l}$ uric acid. See results section for further details of CRUN mutants (chlorate resistant mutants able to utilise nitrate as nitrogen source).

\section{(vii) $\chi^{2}$ analyses}

The data obtained from the mutant selection experiments was subjected to a multi-dimensional $\chi^{2}$ analysis. The overall $\chi^{2}$ was calculated with expected values obtained using the appropriate probabilities computed from the overall ratios of the different mutant classes. The $\chi^{2}$ for each two factor interaction was calculated as a normal two-dimensional $n \times m$ contingency $\chi^{2}$, using the data summed over the other factors. The $\chi^{2}$ for a three-factor interaction was calculated by subtracting the contingency $\chi^{2}$ 's for the appropriate two-factor interactions from the overall $\chi^{2}$ for the three-dimensional table. In the third series of experiments, the $\chi^{2}$ for the four-factor interaction was obtained by subtracting the $\chi^{2}$ 's for the two-factor and threefactor interactions from the overall $\chi^{2}$ for the four-dimensional table.

\section{Results}

\section{(i) Chlorate-resistant mutants selected on different nitrogen sources}

The first series of experiments, the results of which are given in table 2, was designed to detect whether the ratio of niaD mutant to $c n x$ mutants, obtained when selecting for chlorate resistance, varied according to the nitrogen source used. A sample of approximately 200 resistant strains was 
范

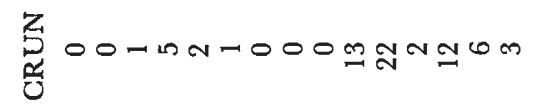

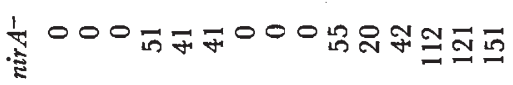

产䞤

䆑

.

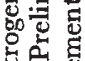

记

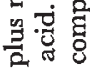

$0^{\infty} \cdot 0$

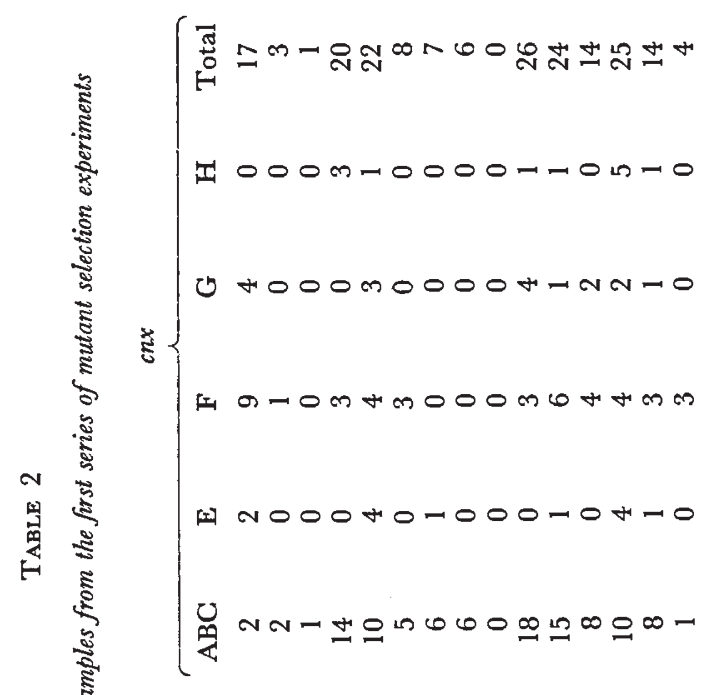

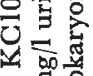

हू

8

\&芦莺

薦芫

密

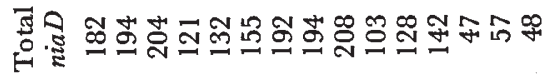

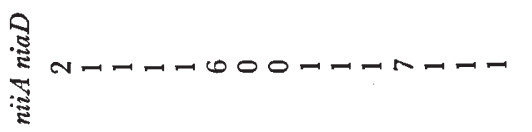

है

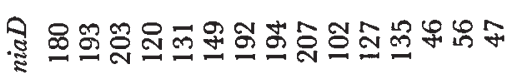


obtained from three different strains using five different nitrogen sources. Experimental details are given in the legend to table 2 and in the previous section.

The principal findings are as follows:

(1) The proportion of nir $A^{-}$mutants among resistant mutants was greatest when uric acid served as nitrogen source. No nir $A^{-}$mutants were selected when L-glutamate or L-arginine served as nitrogen source. This presumably reflects the finding (Cove, 1975) that nir $A^{-}$mutants are more resistant to $100 \mathrm{mM}$ chlorate than chlorate-resistant niaD and $c n x$ mutants when uric acid serves as nitrogen source, but much less resistant when either L-glutamate or L-arginine serves as nitrogen source. This indicates that selection method A (see methods section) which was employed in the first series of experiments may be biased against the selection of weakly resistant mutants. A different selection procedure was therefore devised (method B, see methods section) to attempt to remove this possible bias (see below).

(2) A new class of chlorate-resistant mutant, able to utilise nitrate (designated GRUN in the tables of this paper) was obtained. Genetic analysis to be published in detail elsewhere shows that at least three genes distinct from the $c n x$, niaD or nirA genes are involved.

(3) About 1 per cent of niaD mutants selected also carried an niiA mutation. This was unexpected, since the chlorate resistance phenotype of niaD niiA double mutants is indistinguishable from that of niaD single mutants. For the statistical analyses of data in this paper niiA niaD double mutants have been lumped with niaD single mutants.

(4) The ratio of niaD to $c n x$ mutants obtained varies significantly for the different nitrogen sources used in the selection procedure $\left(\chi_{4}^{2}=115 \cdot 2\right.$, $\mathrm{P}<0.001)$. The ratio of niaD to $c n x$ mutants also varies significantly for the different strains used $\left(\chi_{2}^{2}=44 \cdot 6, \mathrm{P}<0.001\right)$. The $\chi^{2}$ for the three-factor interaction (niaD to $c n x$ ratio by nitrogen source used by strains) is also significant however $\left(\chi_{8}^{2}=38.4, \mathrm{P}<0.001\right)$.

(5) The ratio of $n i a D$ to $c n x$ mutants obtained is very different from that obtained in previous studies. Cove and Pateman (1963) found 9 niaD and $29 c n x$ mutants in a sample of mutants obtained non-selectively as nitrate non-utilisers. Rever (1965) in another sample of mutants obtained similarly, found 6 niaD mutants and $21 \mathrm{cnx}$ mutants. It was therefore decided to carry out a second series of mutant selection experiments to see whether the ratio of niaD to $c n x$ was different when nitrate non-utilisation was used as the selective criterion from when chlorate resistance was used.

\section{(ii) Mutants selected as nitrate non-utilisers}

To obtain nitrate non-utilisers, the putrescine starvation technique of Hermann and Clutterbuck (1966) described in the methods section, was used. The strains used for selection must be putrescine auxotrophs; however, since much of the heterogeneity between strains found in the first series of experiments appeared to be due to the strain biA1 puA2 pyroA4, two new putrescine auxotrophs puA2 and yal puA2 were used. The putrescine starvation technique works best with a mutagenised spore suspension, and so conidiospores treated with NTG were used. The same spore suspension was also used for the selection of chlorate resistant strains using method A, described in the methods section. The results of this series of experiments are given in table 3 . 


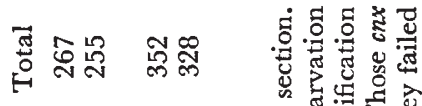

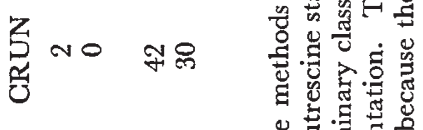

$$
\begin{aligned}
& \text { : } \\
& \text { 若密 }
\end{aligned}
$$

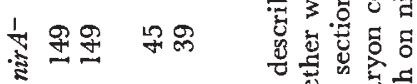

$$
\begin{aligned}
& \text { สิ }
\end{aligned}
$$

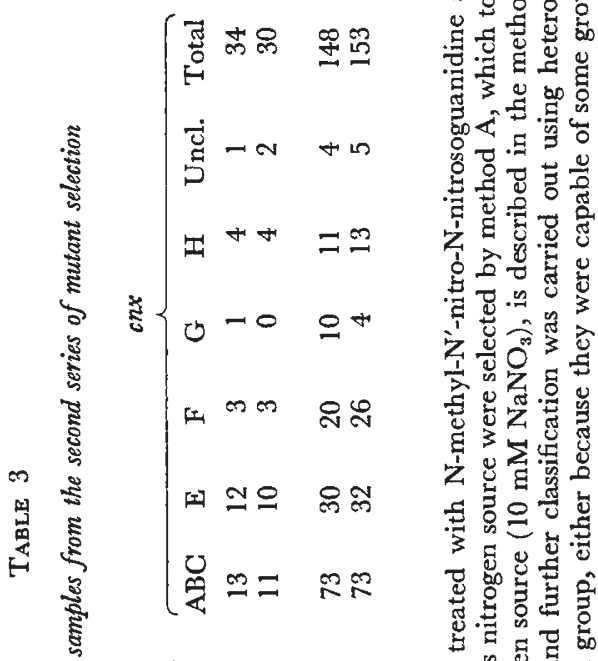

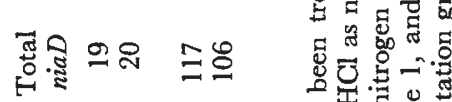

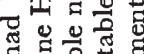

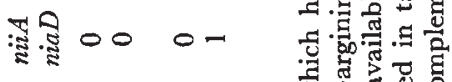

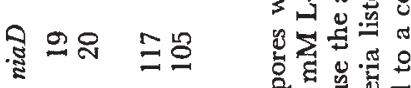

$$
\begin{aligned}
& \text { ฐ }
\end{aligned}
$$

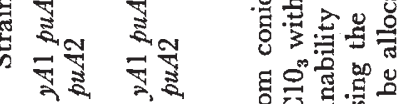

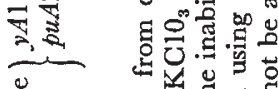

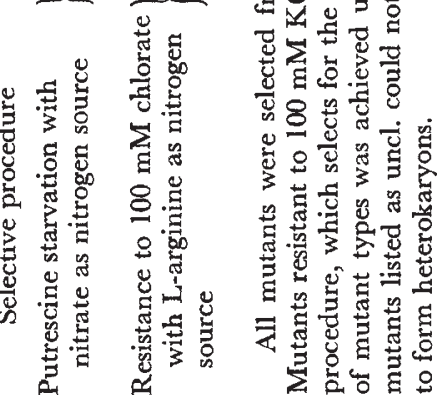


The principal findings are as follows:

(1) As is to be expected, no niiA mutants were obtained when the selective criterion was chlorate resistance, and no chlorate-resistant, nitrateutilising mutants were obtained with the putrescine starvation technique where nitrate non-utilisation is the selective criterion.

(2) nir $A^{-}$mutants are relatively much commoner among the sample of mutants obtained by putrescine starvation than among the sample obtained as chlorate-resistant.

(3) niiA niaD double mutants are much less common in the samples obtained in this series of experiments than they were in those in the first series.

(4) The ratio of niaD to $c n x$ mutants is not significantly different in the sample of mutants obtained by the two methods $\left(\chi_{1}^{2}=0 \cdot 78, \mathrm{P}>0 \cdot 3\right)$. The ratio is also much nearer that obtained previously by either Cove and Pateman (1963) or Rever (1965) described above. There was no significant difference in the ratio of niaD to cnx mutants obtained in the samples from the two strains used $\left(\chi_{1}^{2}=0 \cdot 26, P>0.05\right)$. The $\chi^{2}$ for the remaining interactions were also not significant.

\section{(iii) Effects of mutagenesis on proportions of different mutant classes}

The ratio of niaD to $c n x$ mutants obtained in the sample of chlorateresistant mutants in this second series of experiments differed considerably from that obtained with the similar treatment in the first series of experiments described above. The mutants in the first series of experiments were spontaneous, whereas those in the second were obtained after treatment with NTG. A third series of experiments was therefore carried out to see whether the differences observed were due to the mutagenic treatment. In order to eliminate as far as possible both bias in favour of a particular morphology of resistant mutant and differences in technique in the isolation of the samples of spontaneous and NTG-induced mutants, resistant mutants were obtained using method B as described in the methods section. This series of experiments was also designed to see whether the ratio of niaD to cnx mutants was different when chlorate-resistant mutants were selected with L-arginine as nitrogen source from when uric acid was used. The results are given in table 4.

The main findings may be summarised as follows:

(1) As in the first series of experiments, there was a far higher proportion of nir $A^{-}$mutants in the samples selected with uric acid as nitrogen source than with L-arginine.

(2) Chlorate-resistant mutants able to use nitrate comprised about 20 per cent of the sample of chlorate-resistant mutants obtained after NTG treatment with uric acid as nitrogen source, but were infrequent in the other samples. The majority of such mutants obtained in the uric acid sample were of a type which were not chlorate resistant on arginine, and preliminary genetic analysis indicates that this type is likely to result from mutation in a single gene. The relatively higher frequency of such mutants in the sample obtained on uric acid after mutagenic treatment might therefore result from this gene containing one or more NTG mutational hot-spots.

(3) niiA niaD double mutants were obtained only in the samples obtained 


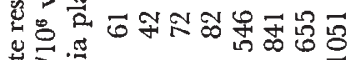

要:

运起

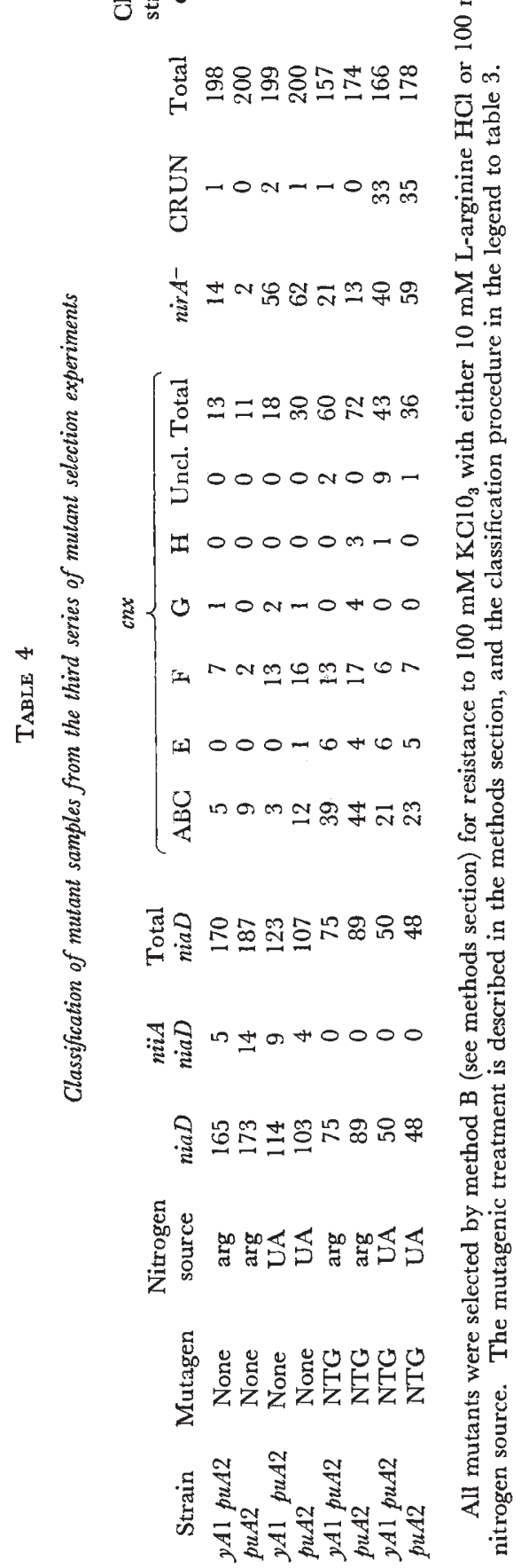

है

?ृ్ల

参

$\overline{80}$

8

के का

霖

용

究递

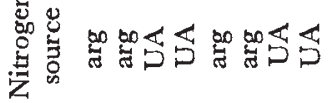

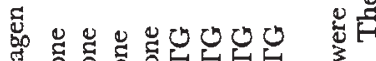

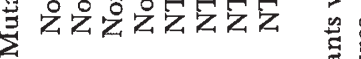

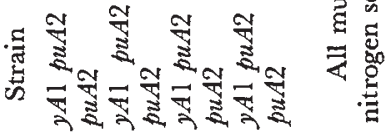


without mutagenic treatment, where they comprised about 5 per cent of all niaD mutants selected.

(4) The $\chi^{2}$ analysis of the data for the ratio of niaD to $c n x$ mutants shows that the only significant two-factor interaction is for the ratio of niaD to $\mathrm{cnx}$ obtained with and without mutagenic treatment $\left(\chi_{1}^{2}=166 \cdot 6, \mathrm{P}<0 \cdot 001\right)$. The total numbers of niaD and $c n x$ mutants obtained from the samples without mutagen is 587 and 72 respectively, whereas with mutagen the corresponding numbers are 262 and 211. The overall ratio of niaD to $c n x$ mutants obtained with L-arginine as nitrogen source is not significantly different from that obtained with uric acid $\left(\chi_{1}^{2}=3.44, \mathrm{P}>0.05<0 \cdot 10\right)$. However, the three-factor interaction term, ratio of niaD to $n x x$ mutants by nitrogen source by mutagenic treatment, is significant $\left(\chi_{1}^{2}=5.24, P>0.02<0.05\right)$. Thus the ratios of niaD to $c n x$ mutants obtained with L-arginine and uric acid as nitrogen source without mutagenic treatment (357:24 and 230:48 respectively) are likely to be different, whereas the equivalent ratios obtained with mutagen (164:132 and 98:79 respectively) are likely to be similar. There was no evidence for there being a difference between strains with respect to the ratio of niaD to $c n x$ mutants obtained $\left(\chi_{1}^{2}=0 \cdot 09, \mathrm{P}>0 \cdot 7\right)$. None of the $\chi^{2}$ 's for the other interactions was significant.

(5) The technique used in this third series of experiments enables the approximate rate of occurrence of chlorate-resistant mutants per viable conidiospore plated to be calculated. These figures are included in table 4 .

\section{Discussion}

The series of experiments described in this paper were carried out because data from preliminary experiments had indicated that the ratio of niaD to $c n x$ mutants, obtained among a sample of mutants selected as chlorate resistant, varied depending on which nitrogen source was used. The results of the first series of experiments provide evidence that this ratio does vary between nitrogen sources. However, the first series of experiments generated proportionally far fewer $c n x$ mutants than previous studies in which selection was made for the inability to utilise nitrate. The second series of experiments showed that, for mutants obtained after mutagenic treatment, there was no significant difference between selection for chlorate resistance (with Larginine as nitrogen source) and selection for the inability to utilise nitrate. The third series of experiments showed that the small proportion of $c n x$ mutants obtained in the first series of experiments, and the greater proportion obtained in the second series, were a consequence of whether or not mutagen was used. c $n x$ mutants are much commoner relative to niaD mutants among samples of chlorate-resistant mutants selected after a mutagenic treatment than among samples of spontaneous mutants. A possible explanation might be that one or more of the $c n x$ genes is particularly sensitive to NTG mutagenesis. Table 5 shows the proportions of the various classes of $c n x$ mutant obtained in three previous studies, and in the series of experiments described here. The sample sizes in some cases are small, and statistical analysis has not therefore been carried out. However, the relative frequency of each class of $c n x$ mutant is similar in each sample, and no mutant type appears to be markedly more frequent after mutagenic treatment. The increase in the ratio of $c n x$ to niaD mutants, in samples obtained after mutagenic treatment, 
does not therefore appear to arise as a result of a particular $c n x$ gene being more susceptible to mutagenic treatment than the other $c n x$ genes or the nia $D$ gene. It seems rather that the niaD gene must be relatively less susceptible to mutagen.

niiA niaD double mutants occurred in almost all the samples of spontaneous mutants, and were absent (except for one mutant) in the samples

\section{TABLE 5}

Percentage of each class of $\mathrm{cnx}$ mutant in various mutant samples

\begin{tabular}{|c|c|c|c|c|c|c|c|c|}
\hline \multirow[b]{2}{*}{ Source of sample } & \multirow[b]{2}{*}{ Selection procedure } & \multirow[b]{2}{*}{ Mutagen } & \multirow[b]{2}{*}{$\begin{array}{c}\text { Sample } \\
\text { size }\end{array}$} & \multicolumn{5}{|c|}{$\%$ of $c n x$} \\
\hline & & & & $\mathrm{ABC}$ & E & F & G & $\mathrm{H}$ \\
\hline $\begin{array}{l}\text { 1st series (see } \\
\text { table 2) }\end{array}$ & Chlorate resistance & None & 191 & 55 & 7 & 23 & 9 & 6 \\
\hline $\begin{array}{l}\text { 2nd series (see } \\
\text { table } 3 \text { ) }\end{array}$ & $\begin{array}{l}\text { Inability to utilise } \\
\text { nitrate }\end{array}$ & NTG & 61 & 39 & 36 & 10 & 2 & 13 \\
\hline $\begin{array}{l}\text { 2nd series (see } \\
\text { table } 3 \text { ) }\end{array}$ & Chlorate resistance & NTG & 292 & 50 & 21 & 16 & 5 & 8 \\
\hline $\begin{array}{l}\text { 3rd series (see } \\
\text { table 4) }\end{array}$ & Chlorate resistance & None & 72 & 40 & 1 & 53 & 6 & 0 \\
\hline $\begin{array}{l}\text { 3rd series (see } \\
\text { table 4) }\end{array}$ & Chlorate resistance & NTG & 199 & 64 & 11 & 22 & 2 & 2 \\
\hline $\begin{array}{l}\text { Cove and } \\
\text { Pateman (1963) }\end{array}$ & $\begin{array}{l}\text { Inability to utilise } \\
\text { nitrate }\end{array}$ & UV & 29 & 52 & 24 & 14 & 3 & 7 \\
\hline Rever (1965) & $\begin{array}{l}\text { Inability to utilise } \\
\text { nitrate }\end{array}$ & Diethyl sulphate & 21 & 43 & 19 & 24 & 5 & 10 \\
\hline $\begin{array}{l}\text { Alderson and } \\
\text { Hartley (1969) }\end{array}$ & $\begin{array}{l}\text { Resistance to } 2- \\
\text { thioxanthine }\end{array}$ & None & 6 & 50 & 33 & 0 & 0 & 17 \\
\hline $\begin{array}{l}\text { Alderson and } \\
\text { Hartley (1969) }\end{array}$ & $\begin{array}{l}\text { Resistance to } 2- \\
\text { thioxanthine }\end{array}$ & NTG & 33 & 39 & 18 & 33 & 3 & 6 \\
\hline $\begin{array}{l}\text { Alderson and } \\
\text { Hartley (1969) }\end{array}$ & $\begin{array}{l}\text { Resistance to } 2- \\
\text { thioxanthine }\end{array}$ & Nitrous acid & 11 & 36 & 36 & 9 & 9 & 9 \\
\hline $\begin{array}{l}\text { Alderson and } \\
\text { Hartley (1969) }\end{array}$ & $\begin{array}{l}\text { Resistance to 2- } \\
\text { thioxanthine }\end{array}$ & Diepoxybutane & 21 & 38 & 29 & 24 & 0 & 9 \\
\hline $\begin{array}{l}\text { Alderson and } \\
\text { Hartley (1969) }\end{array}$ & $\begin{array}{l}\text { Resistance to } 2- \\
\text { thioxanthine }\end{array}$ & Diethyl sulphate & 12 & 42 & 33 & 8 & 0 & 17 \\
\hline $\begin{array}{l}\text { Alderson and } \\
\text { Hartley (1969) }\end{array}$ & $\begin{array}{l}\text { Resistance to 2- } \\
\text { thioxanthine }\end{array}$ & ICR-170 & 17 & 35 & 41 & 12 & 12 & 0 \\
\hline $\begin{array}{l}\text { Alderson and } \\
\text { Hartley (1969) }\end{array}$ & $\begin{array}{l}\text { Resistance to 2- } \\
\text { thioxanthine }\end{array}$ & $\gamma$-irradiation & 38 & 50 & 24 & 18 & 3 & 5 \\
\hline $\begin{array}{l}\text { Alderson and } \\
\text { Hartley (1969) }\end{array}$ & $\begin{array}{l}\text { Resistance to 2- } \\
\text { thioxanthine }\end{array}$ & UV & 24 & 33 & 29 & 29 & 4 & 4 \\
\hline Overall total & & & 1027 & 51 & 17 & 21 & 5 & 6 \\
\hline
\end{tabular}

The data given in the first five lines of the table are collated from tables 2-4 of this paper. Other data are from the publications cited, which also give details of the selection procedures, mutagenic treatment and classification procedures employed. Resistance to 2-thioxanthine arises as a result of the loss of xanthine dehydrogenase $I$, an activity requiring the cnx cofactor.

obtained after mutagenic treatment. The rate of occurrence of all types of chlorate-resistant mutant is, however, at lest 10 times higher if a mutagenic treatment is given than if it is omitted (see table 4), and so it is probable that niiA niaD double mutants are not less frequent in absolute terms after mutagenic treatment than they are when no mutagenic treatment is given. Since the niiA and niaD genes map near to one another (Cove, 1970), these double mutants might involve delections. This has recently been shown to be true 
for a number of such double mutants which fail to recombine with a series of point mutants in the nii $A$ and niaD genes which recombine among themselves (Tomsett and Cove, unpublished data). Preliminary studies indicate that deletion mutants may also constitute a fairly frequent class among spontaneous niaD single mutants (Cove, unpublished data). It is not known whether samples of spontaneous $c n x$ mutants also include a similar proportion of deletions, although this would be of interest as the high relative frequency of niaD mutants among samples of mutants obtained without mutagenic treatment might be explicable if the niaD gene were relatively more prone to deletion than the $\operatorname{cn} x$ genes.

The third series of experiments described here was designed not only to test the effect of a mutagenic treatment on the niaD to $c n x$ ratio, but also to see if this ratio was different when L-arginine was used as a nitrogen source from when uric acid was used. The significance of the finding that this ratio was only different in the sample of mutants obtained without mutagenic treatment is not obvious. All niaD mutants obtained with L-arginine as nitrogen source were also resistant to chlorate when uric acid was nitrogen source, and vice versa, whether or not mutagen was used.

It is difficult to see how, providing there is no bias in favour of a particular phenotype of chlorate-resistant mutant, the nitrogen source upon which selection is made can influence the relative proportions of mutant types obtained. Nevertheless, this has been found to be the case in the series of experiments described here. The effect on the proportion of $\operatorname{nir} A$ - mutants is even more marked than that on the relative proportions of niaD and $c n x$ mutants. In the third series of experiments (see table 4), even though a selection method, which should be free of bias, was used, the proportion of nir $A^{-}$mutants among chlorate-resistant mutants when L-arginine and uric acid served as nitrogen source is respectively 4 and 29 per cent for samples where no mutagenic treatment was employed, and 10 and 29 per cent for samples obtained after NTG mutagenesis. Although nir $A^{-}$mutants are much more resistant to chlorate when uric acid serves as nitrogen source than when L-arginine does (Cove, 1975), they are sufficiently resistant to be selected under either condition. Furthermore, nir $A^{-}$conidiospores germinate and give rise to colonies at a similar frequency whether L-arginine or uric acid serves as nitrogen source, and whether or not chlorate is present (Cove, unpublished data), and so variations in the ability of conidiospores of different genotypes to germinate and establish colonies are unlikely to account for the varying proportions of nir $A^{-}$mutants obtained in the experiments described here. The nir $A^{-}$mutants selected on uric acid could not be distinguished phenotypically from those selected on L-arginine, and $\operatorname{nir} A^{-}$mutants selected because of their inability to utilise nitrate also have a similar phenotype (Cove, 1975). The low frequency of nir $A^{-}$mutants after selection on L-arginine does not therefore appear to be a consequence of, for example, a more drastic mutational alteration being required to confer resistance to chlorate when L-arginine serves as nitrogen source than when uric acid does. Even if the selection procedures are biased, the variations in the ratio of niaD to $c n x$ mutants found under certain circumstances would not be accounted for, as these classes of mutants have apparently similar chlorate resistance phenotypes. No variations in the plating efficiency of conidiospores of niaD and $c n x$ mutants on the media used in the experiments described in this paper has been detected (Cove, unpublished data), and so, as was the case with 
nir $A^{-}$mutants, the variation in the proportions of niaD and cnx mutants obtained with the various treatments does not seem likely to be the consequence of any differential viability of conidiospores.

Acknowledgments.-I wish to thank Dr P. O'Donald for guidance with the statistical analysis used, and Drs K. J. R. Edwards and D. W. MacDonald for their helpful comments on the manuscript. I am particularly grateful to Mr A. I. Simpson for his patient technical assistance. This work was supported in part by a grant from the Science Research Council.

\section{ReFERENCES}

ABERG, B. 1947. On the mechanism of the toxic action of chlorate and some related substances upon young wheat plants. Kungl. Lautbrukshögskolans Ann., 15, 37-107.

ADELBERG, E. A., MANDEL, M., AND CHEN, G. c. c. 1965. Optimal conditions for mutagenesis by N-methyl-N'-nitro-N-nitrosoguanidine in Escherichia coli K12. Biochem. biophys. Res. Commun., 18, 788-795.

ALDERSON, T., AND HARTLEY, M. J. 1969. Specificity for spontaneous and induced forward mutation at several gene loci in Aspergillus nidulans. Mutation Res., 8, 255-264.

CLUTTERBUCK, A. J. 1974. Aspergillus nidulans. In Bacteria, bacteriophages and fungi. Handbook of Genetics, ed. R. C. King, vol. I, pp. 447-510. Plenum Press, New York and London.

Cove, D. J. 1966. The induction and repression of nitrate reductase in the fungus Aspergillus nidulans. Biochim. biophys. Acta, 113, 51-56.

Cove, D. J. 1970. Control of gene action in Aspergillus nidulans. Proc. Roy. Soc. Lond., B., $176,267-275$

cove, D. J. 1976. Chlorate toxicity in Aspergillus nidulans. Studies of mutants altered in nitrate assimilation. Molec. gen. Genet. (in the press).

COVE, D. J., AND PATEMAN, J. A. 1963. Independently segregating genetic loci concerned with nitrate reductase activity in Aspergillus nidulans. Nature, Lond., 198, 262-263.

HERMAN, C., AND CLUTTERBUCK, A. J. 1966. A method for selection of auxotrophs by means of "spidery" growth. Aspergillus Newes Letter, 7, 13-14.

MACDONALD, D. W., AND COVE, D. J. 1974. Studies on temperature sensitive mutants affecting the assimilatory nitrate reductase of Aspergillus nidulans. Eur. F. Biochem., 47, 107-110.

MACKINTOSH, M. E., AND PRITCHARD, R. H. 1963. The production and replica plating of micro colonies of Aspergillus nidulans. Genet. Res. Camb., 4, 321-322.

PATEMAN, J. A., COVE, D. J., REVER, B. M., AND ROBERTS, D. B. 1964. A common co-factor for nitrate reductase and xanthine dehydrogenase which also regulates the synthesis of nitrate reductase. Nature, Lond., 201, 58-60.

PATEMAN, J. A., REVER, B. M., AND COVE, D. J. 1967. Genetic and biochemical studies of nitrate reduction in Aspergillus nidulans. Biochem. 7., 104, 103-111.

REVER, B. M. 1965. Biochemical and genetical studies of inorganic nitrogen metabolism in Aspergillus nidulans. Ph.D. dissertation, Cambridge University.

scazzocchio, c. 1974. The genetic determination of molybdoflavoenzymes in Aspergillus nidulans. 7. Less-Common Metals, 36, 461-464. 